\title{
Adsorption of fluoride ions onto naturally occurring earth materials
}

\author{
${ }^{1}$ KARTHIKEYAN, $\mathrm{M} ;{ }^{2}$ GOPAL, $\mathrm{V} ;{ }^{1}{ }^{\text {*ELANGO, K P }}$ \\ ${ }^{1}$ Department of Chemistry, Gandhigram Rural Institute-Deemed University, \\ Gandhigram 624302, India \\ ${ }^{2}$ Tamil Nadu Water Supply and Drainage Board, District Water Testing Laboratory, Theni 625 531, India, \\ *Email: drkpelango@rediffmail.com
}

\begin{abstract}
Batch sorption system using two naturally occurring earth materials (EM) as adsorbents was investigated to remove fluoride ions from aqueous solution. The system variables studied include initial concentration of the sorbate, agitation time, adsorbent dose, $\mathrm{pH}$, co-ions and temperature. The experimental data fitted well to the Freundlich isotherm. The amount of fluoride ions adsorbed per unit mass of the adsorbent was found to be 0.011 and $0.007 \mathrm{mg} / \mathrm{g}$, at $30^{\circ} \mathrm{C}$ from $4 \mathrm{mg} / \mathrm{L}$ fluoride solution, for EM1 and EM2 respectively. Thermodynamic parameters such as $\Delta H^{\circ}, \Delta S^{\circ}$ and $\Delta G^{\circ}$ were calculated which indicates that the removal of fluoride ions is an endothermic process. Kinetic studies reveal that the adsorption follows reversible first order kinetics. X-ray diffraction patterns of the adsorbents before and after adsorption and Dubinin-Radushkevick (D-R) isotherm indicate that the adsorption of fluoride ions onto these materials is a physisorption process. @ JASEM
\end{abstract}

The removal of fluoride from water is one of the most important issues due to the effect on human health and environment. Fluoride in drinking water may be beneficial or detrimental depending on its concentration (WHO 2004). The optimum fluoride level in drinking water for general good health set by World Health Organization (WHO) is considered to be less than $1.5 \mathrm{mg} / \mathrm{l}$. During recent past removal of fluoride from water has been paid more attention in literature by the different technologies (Saha 1993; Chaturvedi et al., 1990; Sivasamy et al., 2001; Ku et al., 2002; Gopal et al., 2007). Current treatment methods can be divided into two categories viz. precipitation and adsorption. Precipitation of fluoride with calcium and aluminium salts has been used to remove fluoride from industrial waste water. Typically lime is used as a calcium source and $\mathrm{Ca}$ (II) ions released from calcium salt interact with fluoride and form $\mathrm{CaF}_{2}$ precipitate. The aluminium salts interact with fluoride in water and form $\mathrm{AlF}_{\mathrm{n}}{ }^{3+}$ and $\mathrm{Al}(\mathrm{OH})_{3-\mathrm{m}} \mathrm{F}_{\mathrm{m}}$ etc. The final concentration of fluoride in the water treated using this method greatly depends on the solubility of $\mathrm{CaF}_{2}$ and aluminium complexes (Saha, 1993). Adsorption is another technique; wherein many adsorbents have been investigated for the removal of fluoride, (Chaturvedi et al., 1990; Sivasamy et al., 2001; Ku et al., 2002; Gopal et al., 2007; Wei et al., 2007).

Certain habitations of the Andipatti revenue block (which is a fluoride endemic region) of Theni district in Tamil Nadu, South India are free from fluoride in their ground waters. Therefore, an attempt has been made to investigate the ability of the earth materials, (EM1 and EM2) taken from those habitations, to adsorb fluoride ions from aqueous solution and to shed some light on the mechanism of interaction between the soil and fluoride ions.

\section{MATERIALS AND METHODS}

All the reagents used were of commercially available high purity analar grade (Merck or Sd-fine, India). Stock solution of fluoride was prepared by dissolving sodium fluoride in doubly distilled water. Naturally available earth materials were collected from Kanavilakku (EM1) and Bodidhasanpatty (EM2) of Andipatti block in Theni district, pulverized, sieved and used as adsorbents. These materials were examined by geologists and found as kankar, which is a deposit often nodules of $\mathrm{CaCO}_{3}$ formed in soils of semi aerid regions, similar to calcrete and cap rocks. It is a yellowish hard and kankery bed and is the combination of $\mathrm{CaCO}_{3}(\sim 60 \%)$ with silica $(\sim 20 \%)$ granules.

Adsorption experiments were carried out by batch sorption method. The concentration of fluoride ions and $\mathrm{pH}$ were measured using ion-selective meter (Eutech Cyberscan 2100). The XRD patterns of the adsorbent before and after adsorption were recorded at the National Institute for Science and Technology, Thiruvananthapuram, India. The zero point charge $\left(\mathrm{pH}_{\mathrm{ZPC}}\right)$ of the adsorbents was determined by $\mathrm{pH}$ drift method (Jia et al., 2002) and it was found to be 6.86 and 6.92 for EM1 and EM2 respectively indicating that the adsorbents were neutral. Experimental variables considered were initial concentration of fluoride ions 2-10 $\mathrm{mg} / \mathrm{l}$; contact time between adsorbent and the fluoride solution 5-60 min; $\mathrm{pH} 3$ 11 ; dosage of the adsorbent $1-10 \mathrm{~g} / 50 \mathrm{ml}$; temperature $30-50^{\circ} \mathrm{C}$ and co-ions viz. chloride, sulphate, nitrate and bicarbonate ions.

The experimental data were analyzed using Microcal Origin (version 6.0) computer software. The goodness of fit was discussed using correlation coefficient, $r$, and standard deviation, sd. 


\section{RESULT AND DISCUSSION}

Effect of contact time and initial concentration: The amount of fluoride adsorbed per unit mass of the adsorbent $\left(Q_{\mathrm{e}}, \mathrm{mg} / \mathrm{g}\right)$ onto the two earth materials were studied and the results indicated that the amount of fluoride adsorbed increased with an increase in the initial sorbate concentration and also with rise in temperature. The amount of fluoride removed per unit mass of the adsorbent is $0.03 \mathrm{mg} / \mathrm{g}$ for EM1 and $0.022 \mathrm{mg} / \mathrm{g}$ for EM2. The variation of $Q_{\mathrm{e}}$ with temperature suggested that the adsorption is an endothermic process. However, this increase is only marginal. This may be due to the fact that as the adsorbents are crystalline in nature, with rise in temperature the pores present in the adsorbents may be enlarged to a very lesser extent leading to a marginal increase in uptake of fluoride ions. The changes in the rate of removal of fluoride may be due to the fact that, initially, all adsorbent sites were vacant and solute gradient was high. A decreasing removal rate particularly towards the end of the experiment indicated possible monolayer of fluoride ions on the outer surface and/or pores of the adsorbent (Parab et al., 2005; Munoz et al., 2006; Saxena et al., 2006).

Table 1. Statistical parameters and isotherm constants for the removal of fluoride by earth materials

\begin{tabular}{|c|c|c|c|}
\hline Isotherm & $\begin{array}{l}\text { Statistical parameter/ } \\
\text { constants }\end{array}$ & EM1 & \\
\hline \multirow[t]{4}{*}{ Freundlich } & $\mathrm{r}$ & 0.996 & 0.992 \\
\hline & sd & 0.024 & 0.031 \\
\hline & $n$ & 1.32 & 1.47 \\
\hline & $K$ & 0.006 & 0.007 \\
\hline \multirow[t]{2}{*}{ Langmuir } & $\mathrm{r}$ & 0.910 & 0.891 \\
\hline & $\mathrm{sd}$ & 18 & 22 \\
\hline$Q^{0}(\mathrm{mg} / \mathrm{g})$ & 0.067 & 0.058 & \\
\hline$b(\mathrm{~L} / \mathrm{mg})$ & 0.084 & 0.128 & \\
\hline \multirow[t]{4}{*}{ D-R Isotherm } & $\mathrm{r}$ & 0.917 & 0.906 \\
\hline & $\mathrm{sd}$ & 0.24 & 0.24 \\
\hline & $\beta\left(x 10^{-7}\right)$ & -5.19 & 3.73 \\
\hline & $E(\mathrm{~kJ} / \mathrm{mol})$ & 0.98 & 1.16 \\
\hline
\end{tabular}

Effect of dose: The amount of fluoride removed as a function of adsorbent dosage $(1-10 \mathrm{~g} / 50 \mathrm{ml})$ at $4 \mathrm{mg} / \mathrm{l}$ of initial fluoride concentration. The results indicated that the removal of fluoride increased with increase in dosages, as expected. From the result it was evident that an optimum dosage of $6 \mathrm{~g} / 50 \mathrm{ml}$ and 8 $\mathrm{g} / 50 \mathrm{ml}$ are required for appreciable removal of fluoride ions for EM1 and EM2 respectively, and hence these amounts were employed as a dose for further studies.

Equilibrium isotherms: The Langmuir (Langmuir, 1918) and Freundlich (Freundlich, 1906) isotherm models were examined, in this study, to describe the adsorption equilibrium. Langmuir isotherm constants were calculated and are listed in Table 1 along with the statistical results of these plots. From the results, it was evident that the correlation of the experimental data via the Langmuir isotherm was poor. The adsorption data have been fitted to the Freundlich isotherm. The statistical parameters and other isotherm constants are also collected in Table 1. The linearity of the figure shows the applicability of the
Freundlich adsorption isotherm. The applicability the Freundlich adsorption isotherm suggested that the uptake of fluoride ions by the earth materials might be due to physicochemical adsorption on heterogeneous surfaces. The results indicated that the adsorption capacity (measured by $\mathrm{K}$ ) of the adsorbents increased with an increase in temperature. Further the value of intensity of adsorption (n) is greater than unity signifies that the forces within the surface layer are attractive (Raichur et al., 2001; Krishnan et al., 2002). The Dubinin-Radushkevick (D-R) (Ghazy and Ragab, 2007) isotherm was used to determine the nature of the adsorption process viz. physisorption or chemisorption. The statistical results along with other isotherm constants are given in Table 1 . The mean sorption energy values range from 0 to $8 \mathrm{~kJ} \mathrm{~mol}^{-1}$ is for physical adsorption and from 9 to $16 \mathrm{~kJ} \mathrm{~mol}^{-1}$ for chemical adsorption (Ghazy and Ragab, 2007; Sari et al., 2007). It is evident from the results that, in the present study, the mean sorption energy are in between the $0-2 \mathrm{~kJ} \mathrm{~mol}^{-1}$ which indicates that the earth materials trap the fluoride ions by physisorption. 


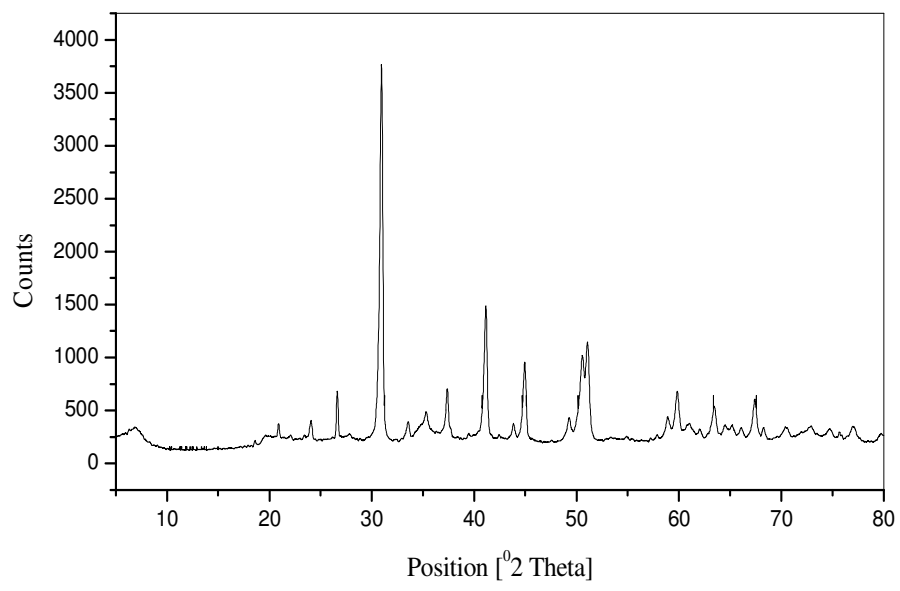

(a)

Thermodynamic parameters. The thermodynamic parameters such as standard free energy, enthalpy and entropy changes were calculated from the temperature dependence of equilibrium constant as explained earlier (Kadirvelu et al., 2002; Stephen Inbaraj and Sulochana 2002). The values of enthalpy change $\left(7-22 \mathrm{~kJ} \mathrm{~mol}^{-1}\right)$ were positive indicating the endothermic nature of the process. Further, the magnitude of the enthalpy changes suggested that the adsorption is a physical process. The positive $\Delta G^{0}$ (0.21-2.11 $\left.\mathrm{kJ} \mathrm{mol}^{-1}\right)$ values indicate that the adsorption process was non spontaneous. The $\Delta S^{0}$

values (16-77) for the adsorption process are positive. This indicated the prevalence of a high degree of disorderliness at the solid solution interface during the adsorption of fluoride onto the adsorbents (Gopal and Elango 2007; Doula et al., 2000). This may be due to the fact that adsorbed water molecules which are displaced by the adsorbate species gain more translational entropy than is lost by the adsorbate molecules. Thus, allowing the prevalence of randomness in the system (Namasivayam and Yamuna 1995).

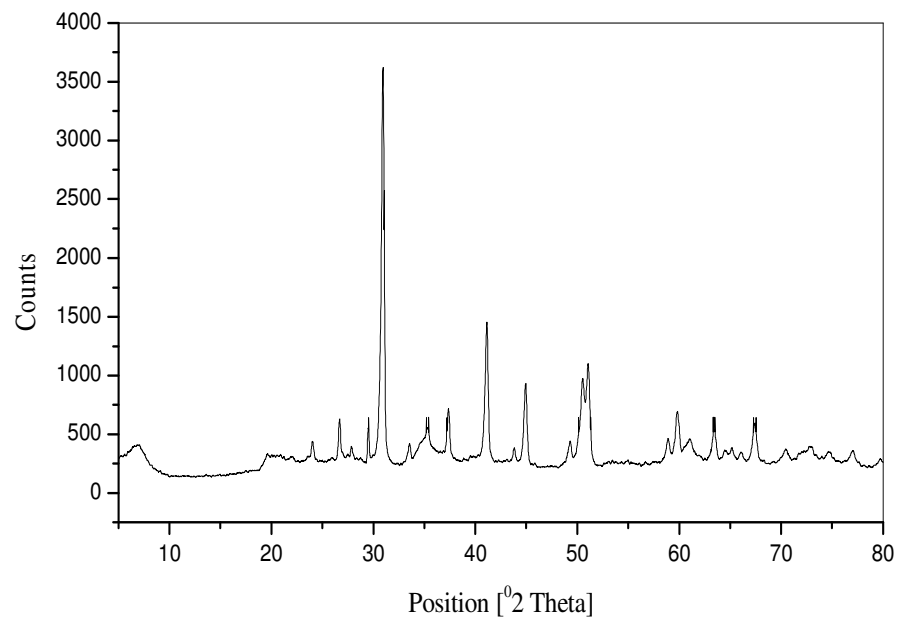

(b)

Fig 1. XRD pattern of EM1 (a) before adsorption (b) after the treatment with fluoride

Effect of $p H$ : To study the influence of solution $\mathrm{pH}$ on the removal of fluoride ions, test mixtures containing $4 \mathrm{mg} / \mathrm{l}$ of fluoride solution and a known amount of the adsorbents $(6 \mathrm{~g} / 50 \mathrm{ml}$ for EM1 and $8 \mathrm{~g}$ $150 \mathrm{ml}$ for EM2) were adjusted to various initial $p \mathrm{H}$ values, agitated for the equilibrium time and analyzed 
for residual fluoride ion concentrations. It is evident from the results that there is no significant change in the amount of fluoride adsorbed in the $\mathrm{pH}$ range 3 9. However, at higher $\mathrm{pH}(=11)$, there was an appreciable reduction in the amount adsorbed. This may be due to the fact that, at this $\mathrm{pH}, \mathrm{OH}^{-}$ions may compete effectively with fluoride ions for the active sites causing a decrease in the amount of fluoride removed (Gopal and Elango 2007).

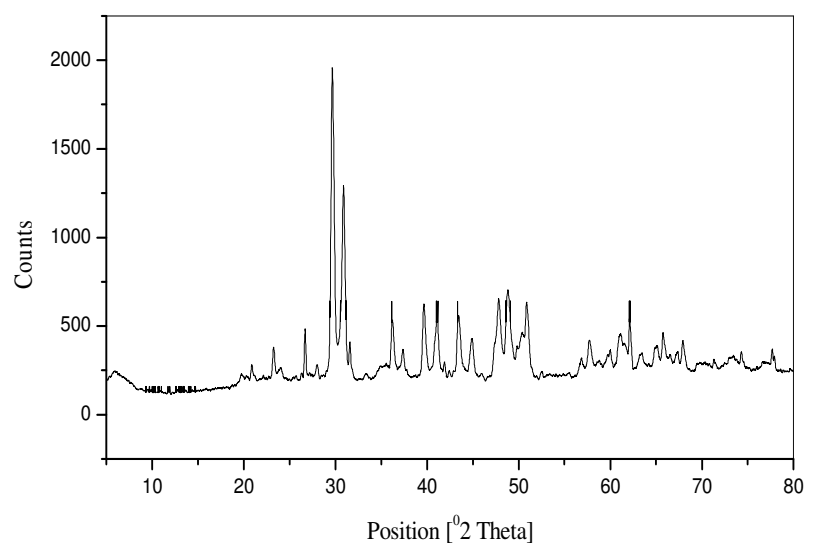

(a)

Effect of co-ions: The effect of added co-ions viz. $\mathrm{Cl}^{-}$, $\mathrm{NO}_{3}{ }^{-}, \mathrm{SO}_{4}{ }^{2-}$ and $\mathrm{HCO}_{3}{ }^{-}$on the amount of fluoride adsorbed is studied and the results indicated that the addition of co-ions, in the concentration ranges investigated, has no appreciable effect on the amount of fluoride ions removed by these adsorbents.

Kinetic modeling: The rate constant for the adsorption, $\mathrm{k}_{\mathrm{ad}}$ was determined using the NatarajanKhalaf equation as described earlier (Kannan and Vanangamudi 1991). The rate constants for the adsorption and forward and reverse processes were calculated from the plot. The results indicated that the $\mathrm{k}_{\mathrm{ad}}$ values increases with increase in temperature suggesting endothermic nature of the adsorption process. Further, an examination of the effect of fluoride ion concentration on the $\mathrm{k}_{\mathrm{ad}}$ values helps to describe the mechanism of removal taking place. In cases of strict surface adsorption, a variation of rate should be proportional to the first power of concentration. However, when pore diffusion limits the adsorption process, the relationship between initial solute concentration and the rate of reaction will not be linear. Hence, in the present study, it seems likely that pore diffusion limits the overall rate of fluoride adsorption (Rengaraj et al., 1999; Weber 1963). Further, the values of $\mathrm{k}_{-1}$ were found to be larger than that of $\mathrm{k}_{1}$ suggesting desorption is dominant over adsorption which lead to lower amount of fluoride adsorption, as observed.

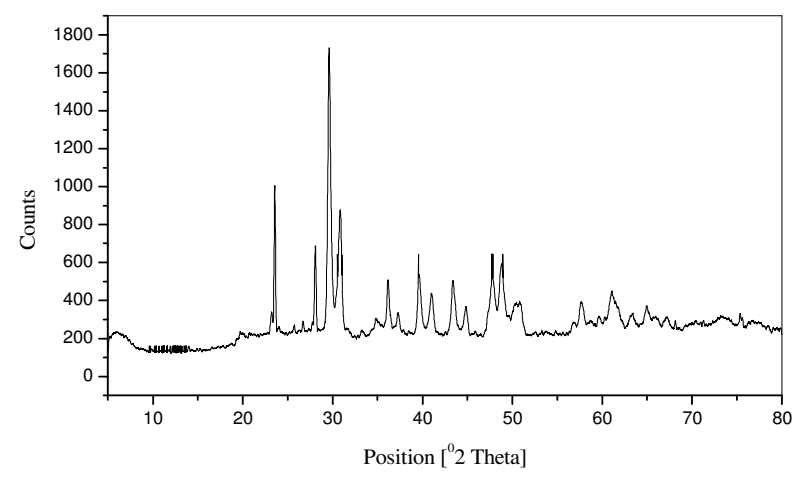

(b)

Fig 2. XRD pattern of EM1 (a) before adsorption (b) after the treatment with fluoride 
Intra-particle diffusion: In adsorption studies, it is necessary to determine the rate limiting step. Therefore, the results obtained from the experiments were used to study the rate-limiting step in the adsorption process. In order to show the existence of intra-particle diffusion in the adsorption process, the amount of fluoride sorbed at time $t$, was plotted against square root of time. The linear portion of the curves does not pass through the origin indicating that the mechanism of fluoride removal by EM1 and EM2 is complex and both, the surface adsorption as well as intra-particle diffusion contribute to the rate determining step (Rengaraj et al., 1999; Shabudeen et al., 2006). The intra-particle diffusion rate constant, $\mathrm{k}_{\mathrm{p}}$, values were obtained from the slop of the linear portions of the curves and were found to be $4.62 \times 10^{-}$ ${ }^{3}, 4.64 \times 10^{-3}$ and $4.65 \times 10^{-3} \mathrm{mg} / \mathrm{g} \mathrm{min}{ }^{0.5}$ for EM1 at $30^{0}$, $40^{\circ}$ and $50^{\circ} \mathrm{C}$, respectively. For EM2 the values were $3.48 \times 10^{-3}, 3.83 \times 10^{-3}$ and $4.71 \times 10^{-3} \mathrm{mg} / \mathrm{g} \mathrm{min}^{0.5}$ at $30^{0}$, $40^{\circ}$ and $50^{\circ} \mathrm{C}$, respectively. The general increase in $\mathrm{k}_{\mathrm{p}}$ values with an increase in temperature may be due to the enlargement of pores present in the adsorbents with rise in temperature.

$X R D$ studies: Adsorption reaction may lead to changes in molecular and crystalline structure of the adsorbent and hence an understanding of the molecular and crystalline structures of the adsorbent and the resulting changes thereof would provide valuable information regarding adsorption reaction (Namasivayam and Yamuna 1995). Hence, the X-ray diffraction (XRD) patterns of the EM1 and EM2 before and after adsorption were recorded and are shown in Fig. 1 and 2, respectively. It was evident from the XRD patterns that the crystal structure of the adsorbents showed no significant changes after the adsorption of fluoride ions. This suggests that the uptake of fluoride ions by the adsorbent was by physisorption (Vemkata Mohan et al., 2001).

Conclusion: The removal of fluoride ions by the two naturally occurring earth materials was found to be endothermic and a non-spontaneous process. The results of isotherm, thermodynamic and XRD studies revealed that the adsorption of fluoride ions onto these materials under investigation was through physisorption. Though the amounts of fluoride ions adsorbed by these adsorbents were low, the results of the present study would definitely add on to the knowledge of the mechanism of interaction of fluoride ions with soils in the natural environment.

\section{REFERENCES}

World Health organization (WHO), (2004) Guidelines for Drinking water Quality. 1, 45.
Saha, S (1993). Treatment of aqueous effluent for fluoride removal. Water Res 27: 1347-1350.

Sivasamy, A; Singh, K P; Mohan, D; Maruthamuthu, M (2001). Studies on defluoridation of water by coalbased sorbents. J Chem Technol Biot 76: 717-722.

$\mathrm{Ku}, \mathrm{Y}$; Chiou, H M (2002). The adsorption of fluoride ion from aqueous solution by activated alumina. Water Air Soil Poll 133: 349-360.

Chaturvedi, A K; Yadav, K P; Pathak, K C; Singh, V N (1990). Defluoridation of water by adsorption on fly ash. Water Air Soil Poll 49: 51-61.

Gopal, V; Elango, K P (2007). Equilibrium, kinetic and thermodynamic studies of adsorption of fluoride onto plaster of Paris. J Hazard Mater 141: 98-105.

Wei, M A; Ya, F Q; Han, M; Wang, R (2007). Characteristic of equilibrium, kinetics studies for adsorption of fluoride on magnetic chitosan particle. J Hazard Mater 143: 296-302.

Fan, X; Parker, D J; Smith, M D (2003). Adsorption kinetics of fluoride on low cost materials. Water Res 37: 4929-4937.

Subhasini, G; Pant, K K (2005). Equlibrium, Kinetics and breakthrough studies for adsorption of fluoride on activated alumina. Sep Purif Technol 42: 265-271.

Das, N; Pattanaik, P; Das, R (2005). Defluoridation of water using activated titanium rich bauxite. J Colloid Interf Sci 292: 1-10.

Jia, Y F; Xiao, B; Thomas, K K (2002). Adsorption of metal ions on nitrogen surface functional groups in activated carbon. Langmuir 18: 470-478.

Munoz, R; Alvarez, M T; Munoz, A; Terrazas, E; Guieysse, B; Mattiassion, B (2006). Sequential removal of heavy metals ions and organic pollutants using an algal-bacterial consortium. Chemosphere 63: 903-911.

Saxena, S, D’Souza, S F (2006) Heavy metal pollution abatement using rock phosphate mineral. Environ Int 32, 199-202.

Parab, H; Joshi, S; Shenoy, N; Verma, R; Lali, A; Sudarsanan, M (2005) Uranium removal from aqueous solution by coir pith: equilibrium and kinetic studies. Biores Technol 96, 1241-1248.

Freundlich, H M F (1906). Over the adsorption in solution. Z Phys Chem A 57: 385-470.

Langmuir, I (1918) Adsorption of gaseous on plane surface of glass, mica and platinum. J Am Chem Soc 40, 1361-1403. 
Krishnan, K A; Anirudhan, T S (2002). A preliminary examination of the adsorption characteristic of $\mathrm{Pb}$ (II) ions using sulpurised activated carbon characteristic from bagasse pith. Indian $\mathrm{J}$ Chem Technol 9: 32-40.

Raichur, A M; Jothi Basu, M (2001). Adsorption of fluoride onto mixed rare earth oxide. Sep Purif Technol 24: 121-127.

Ghazy, S E; Ragab, A H (2007). Removal of copper from water samples by sorption onto powdered limestone. Indian J Chem Technol 14: 507-514.

Sari, A; Tuzen, M; Soylak, M (2007). Adsorption of Pb(II) and $\mathrm{Cr}$ (III) from aqueous solution on Celtek clay. J Hazard Mater B 144: 41-46.

Kadirvelu, K; Sivasankari, C; Jambulingam, M; Pattabhi, S (2002). Activated carbon from parthinium as adsorbent adsorption of $\mathrm{Hg}$ (II) form aqueous solution. Indian J Chem Technol 9: 495-503.

Stephen Inbaraj, B; Sulochana, N (2002). Basic adsorption on a low cost carbonaceous sc 90 kinetic and equilibrium studies. Indian $\mathrm{J}$ _mum Technol 9: 201-208.
Doula, M; Ioannou, A; Dimirkou, A (2000). Thermodynamics of copper adsorption, desorption by Ca-kaolinite. Adsorption 6: 325-335.

Namasivayam, C; Yamuna, R T (1995). Adsorption of direct red 12B, biogas residual slurry: equilibrium and rate processes. Environ Poll 89: 1-7.

Kannan, N; Vanangamudi, A (1991). A Study on Removal of Chromium (VI) by Adsorption on Lignite Coal. Indian J Environ Protec 11: 241-245.

Rengaraj, S; Arabindoo, B; Murugesan, V (1999). Preparation and characterization of activated carbon from agricultural waste. Indian J Chem Technol 6: $1-4$

Weber, W J; Morris, J C (1963). Kinetics of adsorption on carbon from solutions. J Saint Eng Div ASCE 89: $31-60$.

Syed Shabudeen, P S; Venkatesh, R; Selvam, K; Madhavakrishnan, S; Pattabhi, S (2006). Adsorption of congo red dye from aqueous solution using kapok hull carbon. Res J Chem Environ 10: 18-22.

Venkata Mohan, S; Krishna Mohan, S; Karthikeyan, J (2001). IR, XRD, SEM Studies to evaluate the mechanism of azo dye sorption interaction with coal based adsorbents and activated carbon from aqueous phase. J Sci Indus Res 60: 410-415. 